\title{
Colonic obstruction caused by calcified hepatic hydatid cyst migrated into the left colon
}
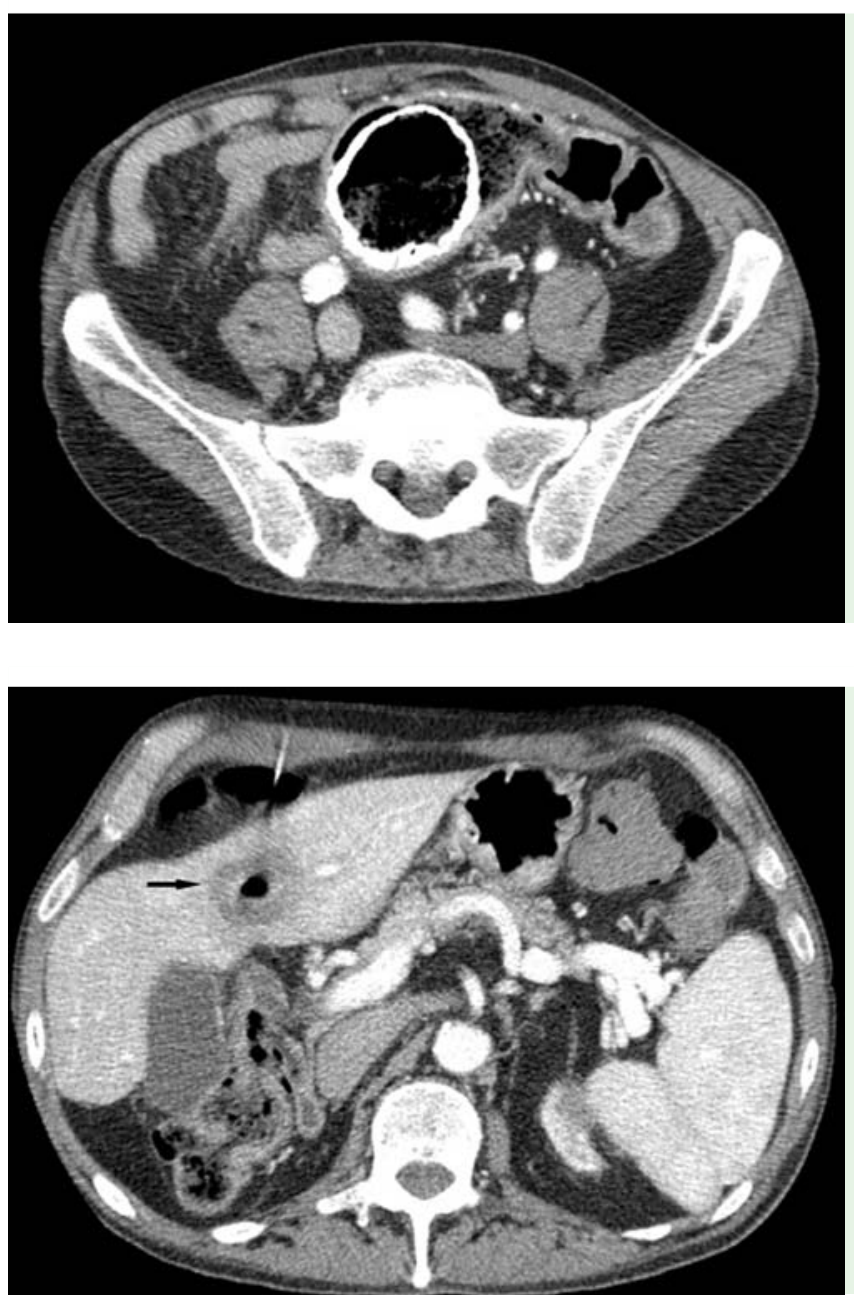

Fig. 1 Computed tomography (CT) scan showing a large ovoidal mass with peripheral calcification within the sigmoid colon.

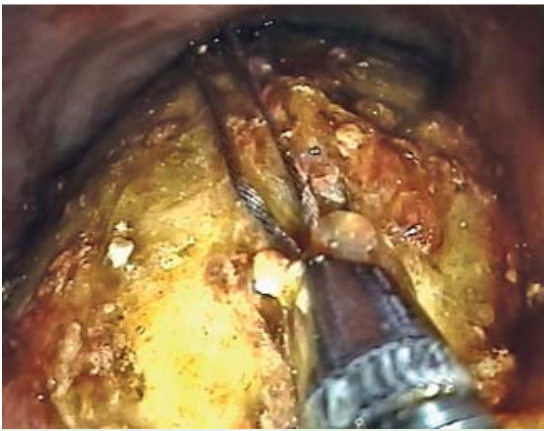

Fig. 3 Endoscopic appearance of the cyst in the sigmoid colon and fragmentation by a lithotripter.

Fig. 2 CT scan showing the hepatic colonic fistula (arrow).
We report a case of hydatid liver disease complicated by migration of an entire calcified cyst into the colon, with subsequent intestinal obstruction.

A 64-year-old man, known to have a calcified asymptomatic hydatid cyst of hepatic segment IV, presented with abdominal pain, nausea, vomiting, and constipation. He was in poor general condition. The abdomen was diffusely tender without guarding and rebound, and there were no palpable masses. A computed tomography (CT) scan showed colonic distention caused by a $6-\mathrm{cm}$ intraluminal ovoidal cystic mass with peripheral calcification in the sigmoid colon ( $\bullet$ Fig. 1 ); the previously reported hepatic hydatid cyst had disappeared and was replaced by a slight hypodensity in continuity with the right colonic flexure, suggestive of a hepaticcolonic fistula ( $\bullet$ Fig. 2).

At sigmoidoscopy the cyst was stuck to the mucosa that presented erosions due to decubitus. Under general anesthesia the cyst was fragmented and removed using endoscopic instruments ( Figs. 3 and Figs. 4). This led to resolution of the obstruction. A colonoscopy was repeated after bowel preparation and this showed a large fistula between the hepatic flexure and the liver. No biliary leakage was observed.

After a 15-month follow-up the patient was well and CT scan and colonoscopy showed a closure of the hepatic-colonic fistula.

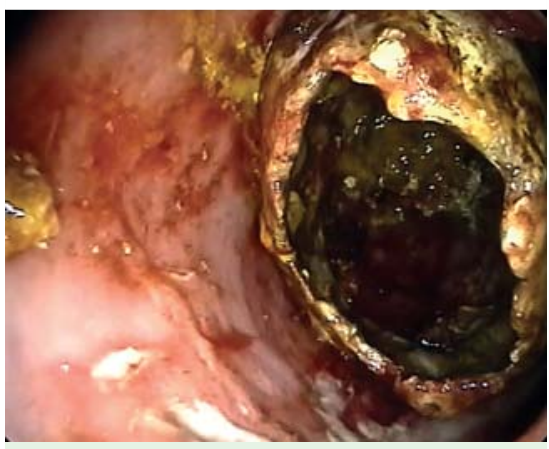

Fig. 4 The cyst after partial fragmentation.

Hydatid cysts may localize almost anywhere in the body [1 - 3], but the majority develop in the liver (65\%) and lungs (25\%) [4]. Intraluminal colonic localization of a hydatid cyst has been reported [5] but the primitive origin of the cyst was not documented and a fistula was not described. Moreover, there was no evidence of obstruction and no treatments were required.

Migration of an entire 6-cm calcified cyst into the colonic lumen through a documented hepatic-colonic fistula and subsequent intestinal obstruction with the same mechanism as a biliary ileus, has never been reported.

\section{Competing interests: None}

Endoscopy_UCTN_Code_CCL_1AD_2AI 


\section{Endoscopy_UCTN_Code_CCL_1AD_2AJ}

\section{A. Restivo ${ }^{1}$, L. Zorcolo ${ }^{1}$, G. D'Alia ${ }^{2}$,} M. Cabras ${ }^{2}$, G. Casula ${ }^{1}$

1 Dipartimento di Chirurgia e Centro Patologia del Colon-Retto, Università di Cagliari, Cagliari, Italy

2 Struttura di Endoscopia Digestiva Chirurgica, Azienda Ospedaliera-Universitaria, Cagliari, Italy

\section{References}

1 Eckert J, Gasser RB, Torgerson PR et al. Geographic distribution and prevalence. In: Eckert JGM, Meslin F-X, Pawlowski ZS (eds). WHO/OIE Manual on Echinococcosis in Humans and Animals: a Public Health Problem of Global Concern Paris: World Organization for Animal Health; 2001: 100-141

2 Abu-Eshy SA. Some rare presentations of hydatid cyst (Echinococcus granulosus). J R Coll Surg Edinb 1998; 43: 347-352

3 Aksu MF, Budak E, Ince U et al. Hydatid cyst of the ovary. Arch Gynecol Obstet 1997; 261: $51-53$

4 Moro P, Schantz PM. Echinococcosis: a review. Int J Infect Dis 2009; 13: 125-133

5 ElFortia M, Bendaoud M, Rashid A. Intraluminal calcified colonic hydatid cyst. Internet J Radiol 2006; 6; 4: No. 2

\section{Bibliography}

DOI 10.1055/s-0029-1244164

Endoscopy 2010; 42: E169-E170

(c) Georg Thieme Verlag KG Stuttgart · New York . ISSN 0013-726X

\section{Corresponding author}

\section{A. Restivo, MD}

Policlinico Universitario Monserrato 09100 Cagliari

Italy

Fax: +39-070-51096436

angelorestivo@tiscali.it 